\title{
POLÍTICAS DE CURRÍCULO PARA O ENSINO MÉDIO NO BRASIL CONTEMPORÂNEO: O QUE ENSINA AOS JOVENS A ESCOLA QUE PROTEGE?*
}

\author{
Roberto Rafael Dias da Silva ${ }^{1}$ \\ Elí Terezinha Henn Fabris ${ }^{1}$
}

\begin{abstract}
RESUMO: No presente estudo problematizam-se os modos pelos quais a lógica da proteção social, enquanto tecnologia política, tem operado como critério orientador dos processos de seleção do conhecimento escolar no contexto analisado. A partir de um conjunto de recorrências empíricas, derivadas da realização de seis entrevistas episódicas, aponta-se que os projetos integrados e interdisciplinares com temas de prevençáo aos riscos sociais são a tônica das pedagogias das proteçóes promovidas contemporaneamente. Suas práticas pedagógicas selecionam e colocam em açáo determinadas formas de conhecimento escolar que tendem a individualizar as responsabilidades coletivas, bem como redimensionar nos currículos escolares as questóes referentes aos danos, perigos e riscos sociais do mundo contemporâneo.
\end{abstract}

Palavras-chave: Currículo. Conhecimento. Ensino Fundamental e Médio.

\section{CURRICULUM POLICIES FOR HIGH SCHOOL IN CONTEMPORARY BRAZIL: WHAT DOES THE PROTECTING SCHOOL TEACH STUDENTS?}

ABSTRACT: This paper aims to wonder how social protection logic as a political technology has worked as a criterion guiding processes of selecting school knowledge in the analysed context. Based on a set of empirical recurrence due to six episodic interviews, we have noted that integrated interdisciplinary projects with themes of prevention against social risks are the major emphasis for contemporary pedagogies for protection. Their pedagogical practices select and put into play particular forms of school knowledge tending to individualise collective responsibilities, as well as reframe questions of social damage, danger and risks in the contemporary world.

Keywords: Primary Education and High School.

\footnotetext{
*Artigo resultado do projeto de pesquisa Políticas Curriculares para o Ensino Médio na América Latina: entre capacidades e oportunidades financiado pelo CNPq.

${ }^{1}$ Universidade do Vale do Rio dos Sinos - São Leopoldo (RS), Brasil. E-mail: robertoddsilva@yahoo.com.br; efabris@unisinos.br

DOI: 10.1590/ES0101-73302016145195
} 


\section{POLITIQUe CURRICUlaire POUR L'ENSEIGNEMENT SECONDAIRE AU BRÉSIL CONTEMPORAIN: QUI ENSEIGNE AUX JEUNES L'ÉCOLE QUI PROTÈgE?}

$R E S U M E$ : La présente étude problématiser la façon dont la logique de la protection sociale en tant que technologie politique, a opéré comme critère d'appréciation de la sélection des processus de connaissance de l'école dans le contexte analysé. Grâce à un ensemble de récurrence empiriques de réalisation six entrevues épisodiques, il est souligné que les projets interdisciplinaires et intégrées avec des thèmes de prévention aux risques sociaux sont le signe des pédagogies des protections promus simultanément. Les pratiques pédagogiques sélectionner et de mettre en action certaines formes de connaissances de l'école qui ont tendance à individualiser les responsabilités collectives, et vous pouvez redimensionner les questions des programmes scolaires concernant les dommages, les dangers et les risques sociaux du monde contemporain.

Mots-clés: Curriculum. Connaissances scolaires. Enseignement Secondaire.

Os Estados já não sancionam mais a apólice coletiva de seguros, deixando a tarefa de obter bem-estar e um futuro em segurança para as buscas individuais (BAUMAN, 2010, p. 59)

$\mathrm{E}$

m elaboração recente, ao descrever a composição de uma nova pauta pedagógica para o Ensino Médio brasileiro, Silva (2014) assinala a constituição de uma pedagogia das proteçóes. Tal configuração pedagógica materializa-se na perspectiva de produção de um conjunto de iniciativas destinadas à intervenção social nas comunidades escolares, visando operar em contextos de riscos, contençóes e vulnerabilidades sociais. Ao aceitarmos como ponto de partida o diagnóstico proposto pelo pesquisador, o presente artigo pretende examinar os modos pelos quais a referida pedagogia das proteções é colocada em ação nas políticas curriculares para o Ensino Médio, atribuindo ênfase para os processos de seleção dos conhecimentos escolares. Em outras palavras, interessa-nos interrogar: o que ensina aos jovens a escola que protege?

Ao estudarmos as políticas curriculares para o Ensino Médio, recentemente direcionamos alguns esforços investigativos para as questões atinentes à ampliação da jornada escolar (CAVALIERE, 2014; SILVA, 2015). De forma mais específica, esse estudo propóe-se a diagnosticar e a compreender os modos pelos quais estamos tratando o conhecimento escolar nas políticas curriculares de ampliação da jornada escolar para o Ensino Médio no Brasil. Acerca do delineamento empírico para esse estudo, optou-se pelo Estado do Rio Grande do Sul devido ao fato de que, neste contexto, ser observado em funcionamento três políticas curriculares que, concomitantemente, recomendam a ampliação da jornada para esta etapa da Educação Básica, a saber: 
1. a implantação do Ensino Médio Politécnico, política em âmbito estadual que estabelece a ampliação da jornada semanal para 30 horas-aula;

2. a adesão da rede pública estadual ao Programa Ensino Médio Inovador (PROEMI), do Ministério da Educaçáo, no qual as atividades pedagógicas das escolas de baixo Índice de Desenvolvimento da Educação Básica (IDEB) foram complementadas com oficinas e outras dinâmicas de diversificação curricular;

3. escolas de tempo integral, ainda em um formato aproximado aos Centros Integrados de Educação Pública (CIEP's), herdadas do início da década de 1990 da administração do Partido Democrático Trabalhista no referido contexto.

Assim sendo, no presente estudo serão problematizados os modos pelos quais a lógica da proteção social, enquanto tecnologia política, tem operado como critério orientador dos processos de seleção do conhecimento escolar no contexto analisado. A partir de um conjunto de recorrências empíricas, derivadas da realização de seis entrevistas episódicas, neste artigo apontaremos que os projetos integrados e interdisciplinares com temas de prevenção aos riscos sociais são a tônica das pedagogias das proteções nesta instituição. Suas práticas pedagógicas selecionam e colocam em ação determinadas formas de conhecimento escolar que tendem a individualizar as responsabilidades coletivas, bem como redimensionar nos currículos escolares as questóes referentes aos danos, perigos e riscos sociais do mundo contemporâneo.

O artigo foi organizado em três seções. Na primeira, alguns apontamentos foram realizados sobre os itinerários investigativos da pesquisa desenvolvida. A seguir, na segunda parte, são descritas sociologicamente as condições de uma economia das proteçóes em curso na sociedade contemporânea. Por fim, na terceira e última seção, é apresentado o material empírico e sobre os quais são tecidas algumas análises das práticas curriculares desenvolvidas no Ensino Médio, mostrando que projetos integrados e interdisciplinares tomam a cena com temas de proteçáo ao risco social. $\mathrm{O}$ artigo é finalizado ao serem lançadas outras questóes para que seja possível o prosseguimento do estudo.

\section{Itinerários investigativos: apontamentos}

Para o desenvolvimento do estudo, do qual este artigo é derivado, se parte do pressuposto de que os estudos sobre os currículos escolares, em contextos de reforma, ainda apresentam intensa potencialidade analítica (MOREIRA, 2010; PACHECO, 2006). Tal dimensionamento mostra-se relevante em nosso tempo, dentre outros motivos, na medida em que diferentes formas de pensamento 
curricular assentam-se em "uma tese educacionista que atribui à educação o desenvolvimento nacional e global, o progresso individual e social dos indivíduos, a solução dos conflitos étnicos, religiosos ou ideológicos, assim como as diferenças socioeconômicas" (DIAZ-BARRIGA, 2013, p. 352). Em outra direção, partimos de uma perspectiva teórico-metodológica que escapa da possibilidade de posicionar a escola como "um tipo de agência de entregas, que deve se concentrar em resultados e prestar pouca atenção ao processo ou ao conteúdo do que é entregue" (YOUNG, 2007, p. 1291). Assim sendo, conforme é sublinhado anteriormente, uma abordagem investigativa foi estruturada atribuindo centralidade ao conhecimento escolar enquanto objeto privilegiado de análise (MOREIRA, 2013; GABRIEL; CASTRO, 2013; GALIAN, 2015; SILVA; PEREIRA, 2013), porque o consideramos objeto central de um currículo comprometido com setores sociais com menores condiçóes de acesso ao conhecimento por outros meios que não através da escola.

Para nossa investigação, em particular, estruturamos metodologicamente seu desenvolvimento em três etapas articuladas. Na primeira etapa, inicialmente, foi realizada uma revisão da literatura da temática central do estudo (SILVA; PEREIRA, 2013). Foi buscado, em diferentes bases de dados brasileiras, sistematizar as principais tendências teóricas e empíricas para o tratamento analítico das políticas do conhecimento escolar. Ao mesmo tempo, foi desencadeada uma revisão conceitual da temática em diferentes tradições investigativas dos Estudos Curriculares. Ao final desta etapa, foi concluído que as pesquisas sobre o conhecimento escolar em nosso País, mesmo que apresentem significativa densidade teórica, ainda estruturam-se a partir de poucos estudos empíricos (SILVA; PEREIRA, 2013).

$\mathrm{Na}$ segunda etapa, prevista para esta movimentaçáo investigativa, foi realizada uma análise documental dos principais textos curriculares que ordenaram as práticas curriculares do Ensino Médio no referido contexto investigativo. Tomando como base esse levantamento, foi efetuada a seleçáo dos documentos a serem investigados. Para a seleção, foram trabalhados os seguintes critérios:

- $\quad$ etapa da educação básica a que se destina;

- $\quad$ período de publicação;

- repercussão nas políticas de currículo do Ensino Médio do Estado;

- $\quad$ articulação aos documentos publicados pelo Ministério da Educação e pelos organismos internacionais.

Ao final, na terceira fase, a qual alguns delineamentos são apresentados, neste artigo, é produzido um conjunto de inserçōes empíricas em quatro escolas públicas estaduais, reguladas por práticas curriculares diferenciadas, fazendo uso de entrevistas episódicas com gestores escolares, visitas à escolas e análises de projetos escolares. No contexto do Estado do Rio Grande do Sul, conforme é 
sinalizado acima, recentemente foi implementada uma nova política curricular intitulada "Ensino Médio Politécnico" (que vigorou entre os anos de 2011 e 2014). A referida política trazia como principais ênfases a ampliação da jornada escolar, o desenvolvimento de seminários de integração curricular e a opção por modelos de avaliação diferenciados. No limite, sua preocupaçấo estava em melhorar os indicadores educacionais do Estado, contribuir para o desenvolvimento econômico e proteger os jovens dos contextos urbanos de vulnerabilidade social. Para a composição investigativa, proposta para este texto, foram examinados os seguintes aspectos: concepçôes de conhecimento escolar, sistemas de raciocínio pedagógicos mobilizados, modalidades de organizaçáo das práticas escolares e relaçóes entre políticas públicas e escolarização.

Para o desenvolvimento dessa parte do estudo, é feita a realização de seis entrevistas episódicas com professores e coordenadores pedagógicos que atuam em contextos de ampliação da jornada escolar no Ensino Médio ${ }^{1}$. Para a seleção dos entrevistados, foram operados dois critérios:

1. que coordenassem a implementação dos seminários integrados em suas respectivas instituiçóes ou que, enquanto gestores, acompanhassem seu processo de implementação;

2. que atuassem em escolas da rede pública estadual e que tivessem seu trabalho pedagógico considerado como relevante pelas coordenadorias regionais de educação.

Vale destacar que a opção por esta forma de entrevista remete-se a importância de compreender a experiência dos professores nessa questão, sobretudo para diagnosticar e descrever os modos pelos quais mencionam suas possibilidades de intervenção profissional, bem como os conhecimentos selecionados para suas aulas e os métodos privilegiados para a atuaçáo nessa etapa da educação básica. De acordo com Flick (2009), importante metodólogo,

o ponto de partida para a entrevista episódica é a suposição de que as experiências de um sujeito sobre um determinado domínio sejam armazenadas e lembradas nas formas de conhecimento narrativo-episódico e semântico (p. 172).

Em outras palavras, a entrevista episódica favorece a descrição das experiências dos entrevistados.

Tal estratégia investigativa, ainda de acordo com o autor, permite ao entrevistado produzir uma narrativa sobre questóes específicas de sua vida (em nosso caso, profissional). A partir das experiências, tornando-as um "conjunto narrável", a entrevista episódica "facilita a apresentação de experiências em uma forma geral e 
comparativa, ao mesmo tempo em que assegura que essas situaçóes e episódios sejam contados em sua especificidade" (p. 172). Abarca formas narrativas diferenciadas, fabricando argumentaçóes situacionais, que consideram a possibilidade do próprio indivíduo contar os elementos que julgue mais apropriado. Não tivemos, então, uma preocupação em buscar pela profundidade das dimensóes subjetivas do entrevistado; mas, antes disso, privilegiamos uma descrição de suas experiências.

Conforme a apresentação de Flick (2009), as entrevistas episódicas apresentam vantagens em relação às histórias de vida e às entrevistas narrativas, por exemplo. Isso se deve ao entendimento de que essa abordagem "utiliza a competência do entrevistado para apresentar as experiências dentro do curso e do contexto destas enquanto narrativas" (p. 176). Supóe, então, que os entrevistados sejam solicitados a informar aspectos expressivos de suas trajetórias. Na realização de nossas entrevistas consideramos como foco a experiência profissional dos professores atuantes em contextos de jornada ampliada no Ensino Médio, no que tange a condução do trabalho pedagógico com projetos e a realização de seminários integrados. Assim sendo, consideramos o seguinte percurso no desenvolvimento da investigação:

1. conte suas experiências que envolvam a ampliação da jornada escolar no Ensino Médio;

2. descreva experiências significativas que foram desenvolvidas na sua escola nos últimos anos;

3. comente suas impressóes sobre as atuais reformas curriculares e sua ênfase na atividade dos estudantes;

4. em uma perspectiva ideal, relate sua concepção de conhecimento a ser ensinado aos jovens nas escolas públicas brasileiras.

A partir desse roteiro, é ponderada ainda a importância da ampliação do escopo da entrevista, na medida em que, nesta forma de coleta de dados, "o alcance das experiências não está restrito àqueles elementos que podem ser apresentados em uma narrativa" (FLICK, 2009, p. 176). Sob tais condiçóes, o entrevistador adquire mais opçóes para direcionar a sessão, ao mesmo tempo em que

a situação extremamente unilateral e artificial que acontece na entrevista narrativa é aqui substituída por um diálogo mais aberto, no qual as narrativas são utilizadas apenas como uma forma de dados (p. 176-177).

A referida estratégia permite articular o uso de perguntas e respostas, associado a um estímulo narrativo dos entrevistados. 
Em elaboração mais recente, Flick (2013) expóe que

o objetivo da entrevista episódica é permitir que, para cada área substancial, o entrevistado apresente experiências de forma geral ou comparativa, e, ao mesmo tempo, relate situaçóes e episódios relevantes (p. 118).

Sob essas condiçóes teórico-metodológicas, importa enaltecer que foram priorizados entrevistados que atuavam na rede pública estadual há pelo menos cinco anos e, destes, pelo menos dois anos com inserção em atividades pedagógicas (docência e/ou coordenação) no Ensino Médio. Para fins deste texto, selecionamos aspectos referentes às atividades de pesquisa em seminários integrados, espaço de articulação do trabalho curricular da reforma Ensino Médio Politécnico. Nossa intenção, como já foi assinalado, vincula-se a um diagnóstico das concepçóes de conhecimento escolar emergentes em contextos de ampliação da jornada. A seguir, descreveremos, em uma perspectiva sociológica, o contexto contemporâneo que favorece a emergência e a centralidade da temática das proteçóes sociais.

\section{A economia das proteções: diagnóstico e perspectivas contemporâneas}

O que teria produzido a necessidade de ampliação da jornada escolar em todos os níveis de escolarizaçáo no Brasil? As respostas podem ser dadas tendo como parâmetros diferentes possibilidades analíticas: políticas, econômicas, sociais, culturais, pedagógicas, etc.. Para desencadear um campo de problematizaçôes, o foco desse estudo será buscar entender a racionalidade política que envolve a busca de soluçóes para a educaçáo e, mais especificamente, para o currículo escolar no interior de uma "economia das proteçôes" ou, ainda, na mobilizaçáo de determinadas "pedagogias de proteção" (SILVA, 2014).

Gradativamente, tem-se encontrado nas políticas e práticas curriculares a constituição de mecanismos voltados para a proteção social (SILVA, 2014; TIRAMONTI, 2011; FABRIS; TRAVERSINI, 2013). Ao mesmo tempo em que as sociedades contemporâneas têm esboçado uma aguda preocupaçáo com os perigos, riscos e virtuais danos sociais advindos dos contextos juvenis, vislumbra-se também a produção de alguns consensos em torno de uma necessária vigilância coletiva. Um dos referenciais que escolhemos para abordar criticamente essa questão advém da sociologia de Zygmunt Bauman (2010; 2013a; b). Na abertura de uma recente coletânea de entrevistas com Bauman, David Lyon explica, além dos entrecruzamentos de suas perspectivas de trabalho, os modos pelos quais a vigilância tornou-se uma dimensão chave em nossos dias atuais. 
A noção cunhada pelos autores - Bauman e Lyon - para explorar essa questão é "vigilância líquida" (BAUMAN, 2013b). Na medida em que a vigilância espalha-se por diferentes espaços sociais, bem como as demandas por segurança têm sido multiplicadas pelo uso de novos aparatos tecnológicos, Lyon (2013) defende que ocorre uma suavizaçáo e uma sofisticação dos modos de monitoramento. Em suas palavras, "sem um contêiner fixo, mas sacudida pelas demandas de 'segurança' e aconselhada pelo marketing insistente das empresas de tecnologia, a segurança se esparrama por toda parte” (LYON, 2013, p. 10). Inúmeros pensadores sociais têm explorado esse aspecto de nossa cultura, em muito impulsionados pelo uso da metáfora do "panóptico de Bentham", derivados de alguns estudos de Michel Foucault nos anos de 1970 (FOUCAULT, 1989).

A hipótese de Lyon, reafirmada e problematizada por Zygmunt Bauman, é que, hodiernamente, o modelo do panóptico tem sido deslocado, em virtude das novas possibilidades eletrônicas. Associado a esse aspecto, os autores defendem que há uma conexão entre disciplina e segurança, fazendo com que esta seja transformada em "um empreendimento orientado para o futuro [...], e funciona por meio da vigilância, tentando monitorar o que vai acontecer pelo emprego de técnicas digitais e raciocínio estatístico" (LYON, 2013, p. 12-13). Sendo orientada para o futuro, a segurança adquire $\mathrm{o}$ status de prioridade pública, na medida em que tende a fabricar tranquilidade e recompensa individual.

Outra nuance dessa condição diz respeito a separação entre poder e política, explorada intensamente nas obras dos autores. Enquanto a política continua local, mediando interesses individuais e públicos, o poder existe em um cenário global e extraterritorial. Assim, o próprio poder torna-se veículo de insegurança, pois suas fronteiras são sempre incertas. A conjunção entre esses fatores - mudança nas relaçóes sociais e separação entre poder e política - torna-se uma característica básica da Modernidade descrita por Bauman (2013b). De acordo com o sociólogo, em torno disso agrega-se também "a conexão mútua entre as novas mídias e os relacionamentos fluídos" (p. 14). As novas práticas de vigilância são engendradas a partir de centrais de processamento de dados, nas quais, conforme Lyon (2013), "o novo espetáculo é um drama mais ardiloso, em que 'o poder move-se à velocidade de um sinal eletrônico" (p. 19).

Situando esse controverso debate no âmbito da reconfiguração do Estado Moderno, desenvolvida ao longo do século XX, Bauman (2010) interroga se a atual racionalidade política destina-se a "ajudar ou policiar os pobres" (p. 49). Em sua percepçáo, o Estado Social — forma como nomeia o Estado de Bem Estar - foi desenvolvido para atender aos interesses de uma sociedade de produtores, considerados como soldados para o progresso coletivo. Os desempregados, tal como os reservistas de um exército, precisavam estar em permanente espera para ingressar nas fileiras quando fossem solicitados. Assim sendo, "deviam ser alimentados, vestidos, calçados - era preciso que gozassem de boa saúde e vivessem em condiçóes dignas 
que lhes permitissem ter e manter esse quadro saudável" (BAUMAN, 2010, p. 51). Em outras palavras, nas condições de uma sociedade de produtores, torna-se consenso que o Estado Social promova a seguridade, através de sistemas públicos de saúde, educação e previdência social.

Contemporaneamente, com os deslocamentos nas formas de intervenção coadunadas à emergência das políticas neoliberais, os pobres passam a ser alvo de outras estratégias. Diferentemente de um reservista para a indústria, hoje "o gasto com os pobres não é um 'investimento racional'. Eles são uma dependência perpétua, e não um potencial” (p. 52). Em torno dessa questão, o sociólogo ainda sugere uma alteração nos modos de entendimento da pobreza pelas novas racionalidades do Estado, emergindo formas de criminalização.

Uma das faces da criminalização da pobreza é a individualização das responsabilidades. Se antes o Estado Social funcionava como um "seguro", em nosso tempo é contatado um processo de ampliaçáo das autonomias individuais. Em outras palavras, os indivíduos são abandonados aos seus próprios limites e recursos. "Assim, espera-se que eles divisem soluçóes individuais para problemas socialmente produzidos, e que o façam de modo específico, usando suas próprias habilidades e recursos particulares" (BAUMAN, 2010, p. 59). De acordo com o sociólogo, esse jogo de condiçóes fabrica uma intensificação da insegurança coletiva, ao mesmo tempo em que, de forma ambivalente, dispóe os indivíduos em processos de exacerbaçáo da competitividade, buscando diferenciar-se para melhor escolher os seus percursos. Essa reconfiguração do Estado, associada a uma predominância das questôes ligadas à proteção social, fabricou condiçôes para que outra agenda formativa estruturasse as políticas de escolarizaçáo em uma sociedade de seguridade, como desenvolveremos a seguir.

\section{O conhecimento escolar nas políticas de ampliação da jornada escolar no Ensino Médio}

Sob as condições de uma economia das proteções, descrita sociologicamente na seção anterior, foi constatada na realização das entrevistas episódicas uma intensa preocupação dos professores do Ensino Médio com as questóes ligadas a esse tema. Sustentabilidade ambiental, saúde coletiva, alimentação saudável, violência e criminalidade, ou mesmo sistemas de proteção antivírus eram destacados como temáticas predominantes nos projetos e seminários integrados referentes às políticas curriculares de ampliação da jornada escolar. $\mathrm{Na}$ medida em que há um sentimento de insegurança coletiva, descrito por Bauman (2013a), percebemos também um processo de individualização das formas de intervenção social. Essa questáo também aproxima-se dos processos de seleção dos conhecimentos a serem ensinados no Ensino Médio, como descreveremos a seguir. 
Para que se inicie uma primeira composição analítica, vale a pena destacar uma escola estadual, situada no norte do Rio Grande do Sul, que escolheu trabalhar com seus estudantes do Ensino Médio um projeto de saúde coletiva que versava sobre o câncer. Seu trabalho nos seminários integrados considerou como ponto de estruturaçáo o levantamento de dados estatísticos sobre o município, assim como sobre a situação da enfermidade no país. A partir do levantamento realizado, iniciaram um segundo movimento de coleta de dados específicos sobre seu município. Considerando uma abordagem metodológica centrada na pesquisa-ação, tal como indicado nos documentos orientadores do Ensino Médio Politécnico, optaram pela realização de um estudo coletivo, que, de acordo com sua coordenadora pedagógica, seria de natureza qualiquantitativa. No limite, desejavam chamar a atenção para uma problemática bastante recorrente na cidade. "Como as pessoas pensam o câncer?" - essa questão acompanhou o desenvolvimento das diferentes pesquisas construídas no âmbito do Seminário Integrado.

De acordo com sua coordenadora pedagógica, o foco era a conscientização para as questôes de saúde coletiva, de maneira que as pessoas participassem e contribuíssem para o desenvolvimento do estudo. O excerto abaixo produz um campo de visibilidades para essa questâo.

Atuo no Instituto de Educação, situado em um município do norte do Rio Grande do Sul. Em nossos projetos do ano de 2013 escolhemos como temática central de nossas atividades um projeto intitulado "Juntos contra o câncer". Essa atividade pedagógica, que fez parte da carga horária dos seminários integrados do Ensino Médio, contou com o apoio da prefeitura da nossa cidade. Como fizemos? Escolhemos priorizar naquele ano nos seminários integrados as questóes de conscientizaçáo para a área da saúde, envolvendo os estudantes do segundo ano do Ensino Médio. Nosso objetivo era diagnosticar, através de uma pesquisa comunitária, os casos de câncer ocorridos no município. As açóes buscavam a participação da comunidade em todas as fases do projeto. (Entrevista episódica com Suzana, coordenadora pedagógica, Escola 1 - Grifos nossos).

Para o desenvolvimento da atividade, os estudantes da referida instituição distribuíram cento e vinte questionários para serem respondidos, no período entre março e outubro de 2013. Com o diagnóstico obtido a partir da análise desses dados, sob a orientação da professora coordenadora do referido seminário, procuraram também produzir açôes de resolução de problemas. Em sua organização metodológica, o projeto era composto por mais de vinte etapas, dentre as quais destacavam-se as seguintes: aprovaçáo na Câmara de Vereadores; divulgação nas rádios comunitárias; pesquisa bibliográfica sobre a cidade; levantamento de dados sobre a incidência de câncer; elaboração dos questionários; concurso de 
slogans para a divulgação da atividade; elaboração de fôlder; aplicação de questionário; visitas a centros oncológicos; análise de dados; construção de gráficos, etc.. De acordo com a fala de sua coordenadora, a preocupação orientadora das pesquisas do Seminário, naquele ano letivo, estava em estudar temáticas direcionadas à saúde coletiva, pois assim tornariam os conhecimentos escolares mais atraentes e, ao mesmo tempo, "úteis para uma sociedade com tantos problemas".

Pode-se perceber um sutil direcionamento para as questóes da proteção social no processo de seleção do conhecimento escolar. Reconhecer que este processo é produzido de forma social é uma questáo recorrente nos Estudos Curriculares, na medida em que a literatura da área sugere que se trata de uma seleção que se dá no âmbito social. Do ponto de vista sociológico, com Bauman (2014) constatamos que as formas mais consistentes do individualismo contemporâneo assentam-se na premissa do "faça você mesmo". A resolução dos problemas de saúde coletiva ou mesmo as questóes ligadas à sustentabilidade do planeta foram redimensionadas. Em suas palavras, "nossos medos, tal como tantos outros aspectos da vida num ambiente líquido moderno, foram desregulados e privatizados" (BAUMAN, 2014, p. 98).

$\mathrm{Na}$ mesma direção, em outra incursão empírica, também é encontrado um projeto que versava sobre a temática da saúde coletiva. Entretanto, nesse estabelecimento a justificativa para o desenvolvimento da atividade derivava-se da ênfase atribuída aos materiais da Campanha da Fraternidade, realizada anualmente pela Igreja Católica. De acordo com Marcelo, professor de Geografia na rede estadual há cinco anos, havia uma preocupação em formar para o exercício da cidadania, através de conscientização.

Nossa atividade trazia como título "Formar um cidadão consciente e humano". Nossa escola tem pouco mais de duzentos estudantes matriculados, mas este projeto, em especial, envolveu os projetos desenvolvidos pelos estudantes do segundo ano do Ensino Médio. [...] Para discutir a construção do sujeito "humano e consciente”, escrito em nosso projeto para o Ensino Médio Politécnico, a escola optou em examinar a questáo da saúde, motivada pelo fato desta questáo estar vinculada ao tema da Campanha da Fraternidade, promovida pela Igreja Católica (Entrevista episódica com Marcelo, professor, Escola 2 - Grifos nossos).

A escola examinada, após a escolha do tema, realizou uma pesquisa diagnóstica, na qual foram entregues e recolhidos duzentos e quarenta questionários junto à comunidade escolar. Conforme o professor entrevistado, em uma primeira etapa foram realizadas muitas palestras sobre o tema, envolvendo especialistas e lideranças atuantes na cidade. Naquele contexto, ainda segundo seu relato, as questóes da qualidade de vida são muito valorizadas, desde que a cidade foi classificada como um dos melhores Índices de Desenvolvimento Humano (IDH) do Estado. 
Sobre a efetivação do projeto e a seleção dos conhecimentos a serem ensinados, o grupo partiu de um estudo sistemático sobre as etapas que estruturam uma pesquisa científica. Nessa fase foi utilizado, amplamente, um documentário intitulado "Construção de um celeiro". Ao final do estudo ainda ocorreu uma apresentação pública dos principais resultados obtidos no seminário integrado, na qual cada estudante tornava pública as suas aprendizagens. De modo geral, os projetos versaram sobre obesidade, anemia, bronquite, dentre outras doenças comuns entre os estudantes. O professor, durante a realização da entrevista, enfatizou o projeto sobre a obesidade, no qual pesquisaram sobre as causas, os sintomas e as formas de tratamento. Aprenderam a calcular o Índice de Massa Corporal (IMC) e, de forma lúdica, desenvolveram um jogo nomeado como "Semáforo dos alimentos".

A temática da alimentação saudável foi um dos temas estudados em outra instituição de ensino que acompanhamos na implementação do Ensino Médio Politécnico. Situada na região noroeste do Rio Grande do Sul, a escola direcionou seus esforços para a temática da obesidade infantil. De acordo com Marisa, professora de Biologia, a escolha do tema deveu-se aos modos de vida contemporâneos, consumistas e individualistas, sobre os quais a escola deveria intervir conduzindo aos jovens do Ensino Médio a outros comportamentos alimentares. $\mathrm{O}$ fragmento abaixo evidencia algumas questóes advindas de sua entrevista episódica.

Sou professora de Biologia há muitos anos e nesse ano, com os projetos novos, descobri outros jeitos de discutir com os alunos. Uma das questóes que mais trabalhei, aliás, a escola discutiu muito foi a alimentação saudável. Olha, como os alunos se interessaram! A escola que leciono fica no noroeste do Rio Grande do Sul e escolhemos trabalhar no seminário integrado, como disse antes com um projeto que teve como título "Alimentaçáo saudável para a obesidade infantil". Foi realizado esse projeto em razáo da nossa preocupaçáo com os modos de vida contemporâneos (Entrevista episódica com Marisa, professora, Escola 3 - Grifos nossos).

Para a operacionalização do trabalho as atividades foram distribuídas ao longo dos primeiros dois anos do Ensino Médio. No primeiro ano foi realizada a "formulação teórica" do projeto. No segundo ano, os onze alunos vinculados ao projeto desenvolviam entrevistas junto à comunidade escolar. Para despertar a atenção da comunidade escolar, de acordo com a professora entrevistada, o projeto foi marcado por jogos, paródias e brincadeiras diversas. Posteriormente, foram encaminhados questionários para as cento e doze crianças das séries iniciais do ensino fundamental.

A seguir, durante o desenvolvimento das aulas destinadas ao Seminário Integrado, os estudantes aprenderam a calcular o Índice de Massa Corporal (IMC) que também foram comparados aos dados do Estado. A literatura infantil foi outro foco de atenção das atividades do Ensino Médio Politécnico daquele contexto. 
Segundo a professora Marisa, uma das atividades que obteve maior sucesso entre os estudantes foi a criação de um livro que versava sobre o "jacaré George que foi confundido com um hipopótamo por estar obeso". De forma orgulhosa, nossa entrevistada enfatizava que o projeto foi premiado nacionalmente e que participariam de um evento em outro país.

Para a seleção dos conhecimentos escolares, em geral, foi retomada a importância dos métodos científicos, associada à possibilidade de discutir temáticas contemporâneas ligadas a uma vida saudável. Além de vincular, tal como vimos anteriormente, a um cenário de individualização das responsabilidades, também foi constatado que os currículos caracterizados pela proteção social reinventam a própria noçáo de comunidade (LIPOVETSKY, 2007). Em uma perspectiva pedagógica, Biesta (2014) reitera que "a retórica da responsabilidade opera precisamente sobre a base de uma 'mudança rápida”" (p. 50), caracterizada pela própria reconfiguração da relação que se estabelece entre o Estado e seus cidadãos.

Outra temática bastante evidenciada refere-se à iniciativas de conscientização dos jovens quanto à violência, às drogas e à criminalidade. Em outra instituição de ensino, situada na regiáo noroeste do Rio Grande do Sul, foi encontrada uma ênfase curricular nessas questóes. Sua intenção também era partir de temáticas que interessavam aos estudantes, que tornassem os currículos atraentes e mais próximos das demandas e interesses dos jovens. A questáo da criminalidade, de acordo com uma das professoras da instituição, deveria ter prioridade no Ensino Médio, pois os jovens estariam mais vulneráveis aos riscos que nossa sociedade evidencia.

Me chamo Caroline e sou professora de Língua Portuguesa. Confesso que no começo achei a proposta de mudança no Ensino Médio um pouco estranha, mas depois passei a considerar a proposta muito interessante, pois trabalha a partir das questóes trazidas pelos alunos, deixando o currículo mais atraente. Somos orientadas, nos seminários, a trabalhar somente com os temas que eles gostem e escolham. Não tenho muitos detalhes sobre o trabalho pedagógico que foi feito, fico mais na minha sala. Sei que no ano de 2012 o projeto tratou das questóes das drogas, da violência e da criminalidade. Nossas coordenadoras achavam que a escola tinha um papel importante para tratar de determinados problemas sociais (Entrevista episódica com Carolina, professora, Escola 4 - Grifos nossos).

No ano seguinte optaram por modificar o escopo temático do seminário integrado, trazendo a temática da profissionalização. Entendiam que os jovens tendo um trabalho, ou estando em condiçóes de empregabilidade, já seria uma forma de prevenção à violência. Com essa intençáo, a escola organizou o projeto, de forma articulada, entre os três trimestres letivos. No primeiro trimestre estudaram questóes atinentes ao jovem inserido no mundo do trabalho e suas tecnologias. No segundo trataram a importância dos projetos de pesquisa. No terceiro selecio- 
naram como conteúdo dos Seminários o sistema financeiro, a origem do dinheiro e dos bancos, etc. De acordo com uma das professoras atuantes na escola, percebeu-se uma evoluçáo na qualidade do ensino. Em sua percepçáo, notou-se uma "uma busca incessante e gratificante" de novas aprendizagens que possibilitassem aos jovens compreender e intervir no mundo.

Importa, neste momento, fazer uma ressalva acerca dos modos pelos quais as questôes ligadas ao interesse e à escolha dos estudantes adquirem centralidade nos processos de seleção do conhecimento escolar. Silva (2014), em perspectiva analítica acerca das políticas curriculares para o Ensino Médio, nomeia essa tendência de "dispositivos de customização curricular". Biesta (2014), por outro lado, sinaliza que "a 'eleiçâo' se converteu em uma palavra central neste debate. Não obstante, a eleição tem a ver com a conduta dos consumidores em um mercado no qual seu objetivo é satisfazer suas necessidades" (p. 51). Na mesma direção é importante salientar a ênfase nas pedagogias ativas e em metodologias prazerosas e lúdicas. Parece-nos que nesta "vontade de proteçâo", a escola não assume o ensino como uma função do ofício do professor, mas integra uma autoformação do estudante, decorrente da própria metodologia assumida pelos projetos e seminários integrados. Assim, algumas expressóes que constam no material empírico já apresentado anteriormente devem ser retomadas.

Sou professora de Biologia há muitos anos e nesse ano, com os projetos novos, descobri outros jeitos de discutir com os alunos. Uma das questóes que mais trabalhei, aliás, a escola discutiu muito foi a alimentação saudável.

Neste caso, a professora discute, a escola discute, esse é um novo jeito de ensinar. Vejamos em outra parte da entrevista, já apresentada:

passei a considerar a proposta muito interessante, pois trabalha a partir das questóes trazidas pelos alunos, deixando o currículo mais atraente. Somos orientadas, nos seminários, a trabalhar somente com os temas que eles gostem e escolham.

Aqui, é notória a centralidade no aluno, sendo ele que define as formas curriculares atraentes, através de seus gostos e preferências. Essas ênfases selecionadas tiveram como o objetivo evidenciar que a escola que protege está mais interessada em promover a seguridade e, por isso, o currículo passa a ser adequado às múltiplas funções que essa escola assume para si, desde a prevenção às doenças, seleção de uma alimentação equilibrada até a prevençâo às drogas, violência e saúde financeira de cada um.

Ampliando o escopo de nossa descrição empírica, outra temática recorrentemente encontrada nas práticas pedagógicas do Ensino Médio Politécnico foi a sustentabilidade e as energias renováveis. Uma das instituiçóes em que realizamos incursōes empíricas explorou essa questão buscando estudar alternativas 
de construção sustentável, escolhendo como conhecimento escolar as temáticas ambientais. $\mathrm{O}$ excerto da entrevista abaixo, com a coordenadora pedagógica da escola, evidencia seus procedimentos.

$\mathrm{Na}$ escola que coordeno o Ensino Médio Politécnico eu já trabalho há bastante tempo. Comecei nas séries iniciais, sou pedagoga, e, aos poucos, fui me aproximando do trabalho com os maiores. Gosto do Ensino Médio. Nos seminários, após uma conversa com a comunidade, escolhemos estudar um tema atual, que faz parte da vida de todos nós - o futuro do planeta! Nosso projeto era sobre "energias e construçóes sustentáveis". Não é a primeira vez que trabalhamos com projetos, desde que assumi a coordenaçáo em 2008 sempre fazemos essas atividades. Para te dar um exemplo, com os alunos do segundo ano do segundo ano tivemos como problema de pesquisa a conservação do planeta em relaçáo à construçáo civil. Os professores de todas as disciplinas ajudaram a pensar sobre os métodos da construçáo de casas e prédios e a compreender o uso de materiais sustentáveis a essa forma econômica. Sempre pensamos que cada um deve fazer a sua parte, ainda mais quando o assunto é meio ambiente (Entrevista episódica com Norma, coordenadora pedagógica, Escola 5 - Grifos nossos).

Segundo a coordenadora entrevistada, o processo de seleçâo dos conhecimentos escolares privilegiou, em um momento inicial, um estudo sobre as formas de energia atualmente disponíveis - eólica, fotovoltaica, hídrica, maremotriz, geotérmica e biocombustíveis. A seguir, com a participaçáo de toda a comunidade escolar, desencadearam uma pesquisa sobre formas de desenvolvimento que fossem "realmente sustentáveis". Em um momento posterior, passaram a visitar formas de construção sustentável: iluminação natural, captação de água da chuva, telhado verde, fossas sépticas, canteiros biosséptico, etc.. Intencionavam, de acordo com a coordenadora Norma, verificar procedimentos economicamente viáveis e em harmonia com o meio ambiente. Tal como estudaram, a responsabilidade e a preservação do meio ambiente representam um compromisso com a vida. Ser sustentável, conforme argumentado na entrevista episódica, é ter sabedoria para proteger o próprio futuro, cuidando do "maior bem que possuímos - o planeta". Parece-nos que os cuidados com o planeta, associados aos imperativos de uma vida consciente e saudável, também apresentavam-se como critérios orientadores da escolha dos conteúdos a serem ensinados. Neste caso, a responsabilização de cada sujeito é uma estratégia produtiva para conseguir a parceria indispensável em uma sociedade movida pelo consumo e pela lógica empresarial, de um Estado que precisa contar com a parceria de cada um e de todos.

Por fim, outra prática que recorrentemente pode ser visibilizada nos Seminários Integrados implementados nas escolas estaduais do Rio Grande do Sul diz respeito ao uso das tecnologias digitais. Desperta atençáo um projeto desenvolvido na região da Serra Gaúcha que evidenciou como eixo principal de seu 
trabalho as proteções necessárias aos computadores, tablets e celulares. Os vírus de computador foram considerados como objetos de estudo no terceiro ano do ensino médio, visando produzir medidas preventivas no uso destes equipamentos.

A escola de Ensino Médio que trabalho, localizada na Serra Gaúcha, realizou seu projeto de pesquisa-ação usando formas de diálogo com a realidade dos alunos. Hoje em dia, se tem assunto que eles sabem mais do que nós é informática. Parece que eles já nascem com essa facilidade. Para aproveitar isso, nosso projeto foi sobre o uso de novas tecnologias. Estudamos vários assuntos, como o uso de editores de texto, de Photoshop, de planilhas de cálculo, várias coisas. Mas, o seminário que foi organizado pelo professor de física, foi sobre vírus de computador. Uma coisa que todo mundo tá sempre cuidando. Aqui na escola, por exemplo, nós não deixamos os alunos usarem os seus pendrives em nossos computadores. São pequenas medidas que cada um sempre cuida (Entrevista episódica com Ricardo, professor, Escola 6 - Grifos nossos).

Segundo o professor entrevistado, o projeto contou com significativa participação dos alunos, sendo que eles próprios fizeram uma lista de bons antivírus para disponibilizar gratuitamente aos colegas. Também escreveram textos para publicar no blog da escola sobre alguns cuidados éticos no uso da internet, quando devemos falar ou usar imagens pessoais. A realização do projeto também coincidiu com a divulgação de fotografias íntimas de uma atriz, o que também mobilizou a realização da atividade. Ao final, durante a realização dos seminários integrados, fizeram uma pequena exposição apresentando a "evolução" das técnicas, trazendo celulares, aparelhos de som, televisão e computadores antigos.

\section{Considerações finais}

Ao analisar os excertos das entrevistas e dados descritos acima, desperta atenção a preocupação com a comunidade e com a realização e a divulgação dos projetos. Destaca-se, por exemplo, que um deles foi premiado nacionalmente e apresentado em outro país latino-americano. As pedagogias das proteções agem na subjetivação dos sujeitos em dois planos, um assegurando a proteção, o outro produzindo regulaçóes nas subjetividades (protegidas e protetoras). No plano das proteçóes, pode-se observar nos dados descritos acima todo o investimento nos projetos com conhecimentos sobre a vida saudável e a distância de doenças e vícios. No plano das subjetividades protegidas, estão todos os alunos e comunidade que pretendem atingir e a própria ampliação da jornada escolar. No plano das subjetividades protetoras ainda podemos ver a própria escola de Ensino Médio ser responsabilizada junto com a comunidade pela concretização das proteçôes. 
Com essa análise que foi desenvolvida, é possível chamar atenção para o que nos move quando se está envolvido com esses desenhos curriculares, que não apenas desejam atender de forma significativa e prazerosa o que os alunos desejam como conteúdos escolares, mas que o próprio jeito de entender o currículo é produzido neste momento contemporâneo por meio da vigilância permanente e sistemática. Há um controle para que todos estejam na escola e, longe de riscos, por isso se justifica a ampliação da jornada escolar e que estejam sendo produzidos para uma cultura das proteçóes, favorecendo os conhecimentos que circulam por meio das pedagogias das proteçóes. Objetivamente, é interessante argumentar que, a partir das políticas de ampliaçáo da jornada escolar para o Ensino Médio, novos critérios pedagógicos passam a orientar os processos de seleção do conhecimento escolar nesta etapa da educação básica. Uma "escola que protege", situada sociologicamente em uma nova "economia das proteçôes", contribui diretamente para a composição de novos direcionamentos para a agenda formativa dos jovens brasileiros, em nossas escolas públicas.

Deve ser ressaltado que, mais do que vencer a luta da insegurança para sempre é mais interessante e produtivo, que estejam sempre a buscar por ela, estejam sempre à busca da condição de seguridade. Veiga Neto (2014, p.1), em recente produção sobre o tema "guerras", afirma que "Foucault viu, no caráter sempre diferencial e agônico das relaçóes de poder, o fundo sobre o qual se move a sociedade. Desse modo, as relações sociais são antes, primordialmente, de enfrentamento, de luta, de combate, de guerra enfim". O que pretendemos mostrar é que essa forma de produçấo dos sujeitos por meio de um currículo das proteçôes é adequada para esse momento em que segurança e disciplina se juntam para organizar a vida social. Nesse currículo das proteçóes, torna-se importante que todos estejam protegidos; quer por meio dos conhecimentos (pedagogia das proteçôes), quer por meio das novas subjetividades que se produzem (protetoras e protegidas). Um currículo das proteçóes altera as coordenadas de tempo e de espaço, na medida em que se torna preciso ampliar o tempo e com isso, devem se multiplicar, pois não é possível e nem produtivo que todos permaneçam apenas em suas salas de aula, os projetos que estão sustentados pela pesquisa da realidade, levam alunos e professores para a comunidade, para a rua, para a Câmara de Vereadores.

Nesta direção, talvez seja importante se perguntar se os conhecimentos quando retirados apenas da realidade social ou com esse componente de utilidade para a comunidade não podem deixar alguns conhecimentos necessários e que fazem parte do repertório cultural de uma sociedade em segundo plano, ou nem abordados? Quem sairia perdendo neste tipo de currículo das proteçôes? A forma interdisciplinar de abordagem dos conteúdos também pode fragilizar algumas áreas específicas se não forem suficientemente aprofundados em cada área. Com esses alertas não estamos nos colocando contra as práticas pedagógicas analisadas, mas tensionando a racionalidade que as conduzem, para que ao menos possamos escolher e justificar essas ou outras formas de condução. 
Outra questão que merece atenção é que ao desenvolver projetos voltados para proteções, há um aumento do medo, de um sentimento de que todos precisam estar alertas e preocupados com a sua proteçáo, do outro e do planeta. Neste sentido cresce o medo e a insegurança, ingredientes necessários para manter a todos em luta constante contra os riscos. Voltamos a nossa pergunta inicial: O que ensina aos jovens a escola que protege? Assim, nasce o convite para que se continue avançando em análises dos currículos e pedagogias das proteçôes. Não se deve descuidar dos conhecimentos escolares como foco central de um currículo que pode proteger, mas que tem compromisso com o acesso ao patrimônio cultural em todas as áreas, de forma qualificada. Destaca-se ainda a necessidade da construçáo de pautas pedagógicas mais justas curricularmente, que garantam aos jovens do século XXI, que transitam em escolas de jornada integral, experiências formativas relevantes, que, em nossa leitura, não se esgotam em ações cotidianas restritas à dimensão do fazer.

\section{Notas}

1. Atendendo às disposições éticas da pesquisa com seres humanos, os entrevistados assinaram um termo de consentimento livre e esclarecido e foram identificados com nomes fictícios.

\section{Referências}

BAUMAN, Z. Vida a crédito. Rio de Janeiro: Zahar, 2010. . Sobre educação e juventude. Rio de Janeiro: Zahar, 2013a. . Vigilância líquida: diálogos com David Lyon. Rio de Janeiro: Zahar, 2013 b.

Zahar, 2014.

. Cegueira moral: a perda da sensibilidade na modernidade líquida. Rio de Janeiro:

BIESTA, G. Medir lo que valoramos o valorar lo que medimos? - globalización, responsabilidad y la noción de propósito de la educación. Pensamiento educativo, v. 51, n. 1, p. 46-57, 2014.

CAVALIERE, A. Escola pública de tempo integral no Brasil: filantropia ou política de Estado? Educação e Sociedade, v. 35, n. 139, p. 1205-1222, 2014.

DIAZ-BARRIGA, A. Curriculo, escuelas de pensamiento y su expresión en la tensión entre saberes conceptuales y práticos. Currículo sem Fronteiras, v. 13, n. 3, p. 346-360, 2013.

FABRIS, E.; TRAVERSINI, C. Conhecimentos escolares sob outras configuraçôes: efeitos das movimentaçôes disciplinares e de controle?. In: TRAVERSINI, C. et al. (Orgs.). Currículo e inclusão na escola de ensino fundamental. Porto Alegre: Edipucrs, 2013, p. 33-54.

FLICK, U. Introdução à pesquisa qualitativa. $3^{\mathrm{a}}$ ed. Porto Alegre: Artmed, 2009.

Introdução à metodologia da pesquisa: um guia para iniciantes. Porto Alegre:

Penso, 2013. 
FOUCAULT, M. Vigiar e Punir. Petrópolis: Vozes, 1989.

GABRIEL, C.; CASTRO, M. Conhecimento escolar: objeto incontornável na agenda política educacional contemporânea. Educação em Questão, v. 45, n. 31, p. 82-110, 2013.

GALIAN, C. The curriculum of Brazilian public schools: The relevant knowledge in the teachers? perspective. In: LEITE, C.; MOURAZ, A.; FERNANDES, P. (Org.). Curriculum studies: policies, perspectives and practices. Porto: CIIE, 2015, p. 260-272.

LIPOVETSKY, G. A sociedade da decepção. Barueri: Manole, 2007.

LYON, D. Introdução. In: BAUMAN, Z. Vigilância líquida: diálogos com David Lyon. Rio de Janeiro: Zahar, 2013, p. 9-24.

MOREIRA, A. Lendo Stella: um mote para pensar o fundamental na escola de ensino fundamental. Revista da FAEEBA - Educação e Contemporaneidade, v. 19, n. 34, p. 193205, 2010.

. Currículo e gestão: propondo uma parceria. Ensaio, v. 21, n. 80, p. 547-562, 2013.

PACHECO, J. Uma perspectiva atual sobre a investigação em Estudos Curriculares. Perspectiva, v. 24, n.1, p. 247-272, 2006.

SILVA, R. Políticas de ampliação da jornada escolar para o Ensino Médio no Rio Grande do Sul: um estudo sobre o conhecimento escolar. Ensaio: avaliação e políticas públicas em educação, v. 23, n. 89, p. 869-900, 2015.

. Comunidades como espaço de intervenção pedagógica: um estudo da docência no ensino médio. Revista Brasileira de Educação, v. 19, n. 59, p. 945-966, 2014.

SILVA, R.; PEREIRA, A. Políticas de constituição do conhecimento escolar na pesquisa educacional brasileira. Cadernos de Pesquisa, v. 43, n. 150, p. 884-905, 2013.

TIRAMONTI, G. Educación secundaria argentina: dinámicas de selección y diferenciación. Cadernos de Pesquisa, v. 41, n. 144, p. 692-709, 2011.

VEIGA-NETO, A. Guerras. Jornal da Sociedade Psicanalitica de Porto Alegre, ano 13, n. 26, p. 6, 2014.

YOUNG, M. Para que servem as escolas?. Educação e Sociedade, v. 28, n. 101, p. $1287-$ 1302, 2007.

Recebido em 23 de janeiro de 2015.

Aprovado em 23 de março de 2016. 